ORIGINAL ARTICLE

\title{
Acceptability and Feasibility of Reducing Unsafe Abortion through Medication among Early Pregnant Women who are Attending in RHSTEP at DMCH
}

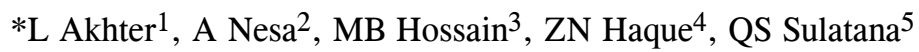 \\ ${ }^{1}$ Dr. Lutfa Akther, Program Co-ordinator, RHSTEP, DMCH \\ ${ }^{2}$ Dr. Ayatun Nesa, Associate Professor, Clinical Patrhology, BIRDEM Genaral Hospital \\ ${ }^{3}$ Dr. Muhammad Belal Hossain, MPH, Department of public health, AIUB \\ ${ }^{4}$ Dr.Zuhaina Noor Hauque, Lecturer of Pharmacology, Ibrahim Medical College \\ ${ }^{5}$ Quazi Suraiya Sultana, Exucative Director, RHSTEP, DMCH \\ *Corresponding Author
}

Date of submission: 05 April $2015 \quad$ Date of acceptance: 19 July 2015

\section{ABSTRACT}

Background: Over the past two decades, the health evidence, technologies and human rights rationale for providing safe, comprehensive abortion care have evolved greatly. Unsafe abortion is one of the four main causes of maternal mortality and morbidity.

Material \& Methods: A prospective study were done from December, 2013 to January, 2015, over 13th months in RHSTEP at DMCH. Pregnant women of 5-9 weeks of pregnancy wanted to terminate their pregnancy were included in this study. Pregnant women had over 9th week of pregnancy, ectopic pregnancy, molar pregnancy and severe anemia were excluded from this study. A total 294 patients were enrolled in this study and MRM service was given them.

Results: Among the 294 patients 268 (91\%) found successful termination of pregnancy and 26 (8.8\%) patients found unsuccessful termination. In these 26 patients, 24 had incomplete abortion and two had viable pregnancy (failed MRM). Most of the patients complained of moderate bleeding (156) and pain (182) after taking medication but some of them revealed excessive bleeding (138) and marked pain relieved by pain killer (112). Some of them also had fever (76), nausea (82), diarrhea (12), vertigo (30) and few also found itching palm (05) and oral ulcer (02). 87\% patients told overall side effects were acceptable and $8 \%$ said natural \& only $5 \%$ found unacceptable. On interview about the satisfaction of the patients in using this method for early termination, $90 \%$ patients were satisfied with this method.

Conclusion: Menstrual regulation with medication (MRM) using mifepristone and misoprostol is a safe, effective and acceptable method for early termination of pregnancy. Expansion of this service will reduce unsafe abortion in our country.

Key Words: Menstrual regulation with medication (MRM), Mifepristone, Misoprostol

\section{Introduction}

Over the past two decades, the health evidence, technologies and human rights rationale for providing safe, comprehensive abortion care have evolved greatly. Despite these advances an estimated 22 million abortions continue to be performed unsafely each year ${ }^{1}$. Unsafe abortion is one of the four main causes of maternal mortality and morbidity. It accounts for $13 \%$ of maternal deaths $^{2}$, and $20 \%$ of the total mortality and disability burden due to pregnancy and childbirth ${ }^{3}$.

Globally about 210 million women become pregnant every year. Of these 75 million ends in still birth and abortion. In 2008 an estimated 21.6 million unsafe abortions were performed worldwide, and almost all were done in developing countries, in which about
47000 women died due to unsafe abortion ${ }^{4}$. Bangladeshi women are at particularly high risk of unwanted pregnancy and unsafe abortion, because unmet need for family planning is higher here than in other regions of the world. In 2010, 372,000 unsafe abortion led to complications, among them 231,000 were treated at health facilities in Bangladesh ${ }^{5}$. So access and availability of safe MR is essential for reducing unsafe abortion and its complication.

Menstrual regulation with medication (MRM) is a globally endorsed method that involves the use of various medicines to evacuate the uterus. Research in the past two decades has identified several highly effective regimens for early medical abortion with a success rate of 93 to 98 percent, consisting of 200 
$\mathrm{mg}$ of mifepristone followed by 400 or $800 \mathrm{mcg}$ of misoprostol ${ }^{6-8}$.

MRM using mifepristone and misoprostol is a safe, effective and acceptable option for $\mathrm{MR}^{9-12}$. Studies consistently show that $85-95 \%$ of women are satisfied with this method ${ }^{13-14}$. MRM services has the potential to greatly improve access to safe abortion because, it is simple to deliver, easy to manage, require less equipment, facilities \& staffing and cost effective than the other methods ${ }^{15}$.

The present study was aimed to assess the acceptability and feasibility of MRM in early pregnant women to reduce the unsafe abortion in resource poor settings like Bangladesh and subsequently helping health policy makers to take necessary strategies to lessen the risk of abortion associated complications and mortality.

\section{Materials and Method}

A prospective study were done from December, 2013 to January, 2015, over $13^{\text {th }}$ months in RHSTEP at DMCH. Pregnant women of 5-9 weeks of pregnancy wanted to terminate their pregnancy were included in this study. Pregnant women had over $9^{\text {th }}$ week of pregnancy, ectopic pregnancy, molar pregnancy and severe anemia were excluded from this study. After details explanation of the procedure and proper counseling to the patients a written informed consent were taken from the patient and data collection sheet were filled up. Then all data have been analyzed and plotted in different chart and diagram.

\section{Results}

A total 294 patients were enrolled in this study and MRM service was given them. The mean age of the enrolled women in the study was 29 years and gestational mean age was 6.3 weeks. Patient's demographic data also reveals that, most of them were educated (complete secondary school) and mostly house wife having 3-4 para on obstetrical history \& commonly used barrier method for family planning (table-1). Among the 294 patients, 235 were come for follow-up and face to face interview were taken up. Remaining 59 patients interviewed over telephone and confirmed no complications. Among the 294 patients 268 (91\%) found successful termination of pregnancy and $26(8.8 \%)$ patients found unsuccessful termination. In these 26 patients, 24 had incomplete abortion and two had viable pregnancy (failed MRM). Overall successful and unsuccessful cases have been shown in the flow chart (Fig-0.1). Among 294 patients, most of the patients complained of moderate bleeding (156) and pain (182) after taking medication but some of them revealed excessive bleeding (138) and marked pain relieved by pain killer (112). Some of them also had fever (76), nausea (82), diarrhea (12), vertigo (30) and few also found itching palm (05) and oral ulcer (02). The patient complains are shown in the bar diagram (Fig-0.2). Though there were some complications in this method, $87 \%$ patients told overall side effects were acceptable and $8 \%$ said natural \& only $5 \%$ found unacceptable. On interview about the satisfaction of the patients in using this method for early termination, $90 \%$ patients were satisfied with this method and they said they will advise their friends and relatives for using this method for early termination of pregnancy.

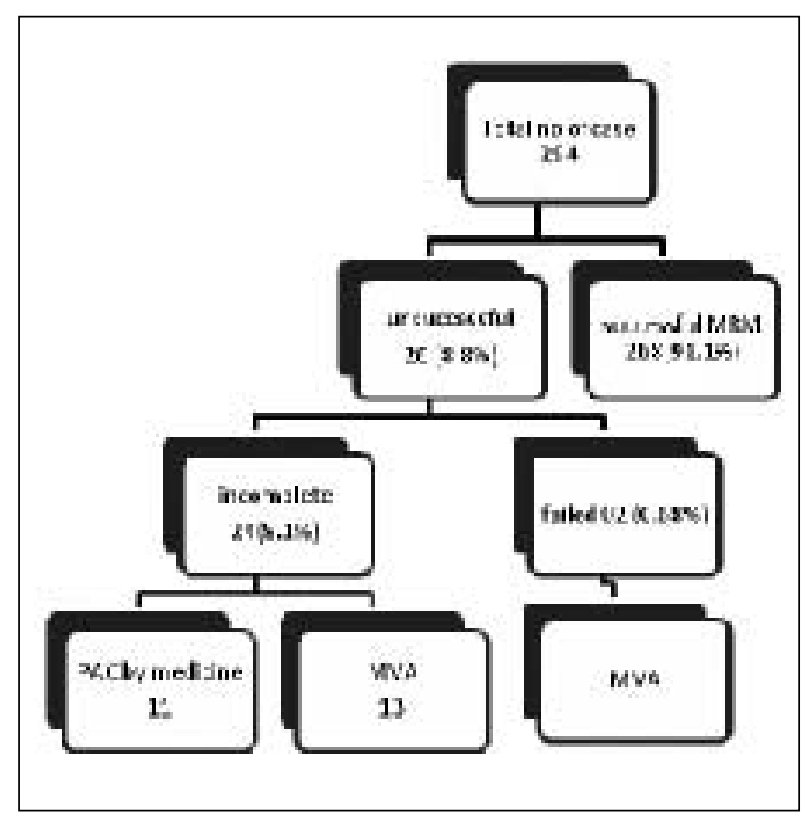

Fig 1: Flow chart of effectiveness of MRM kit 


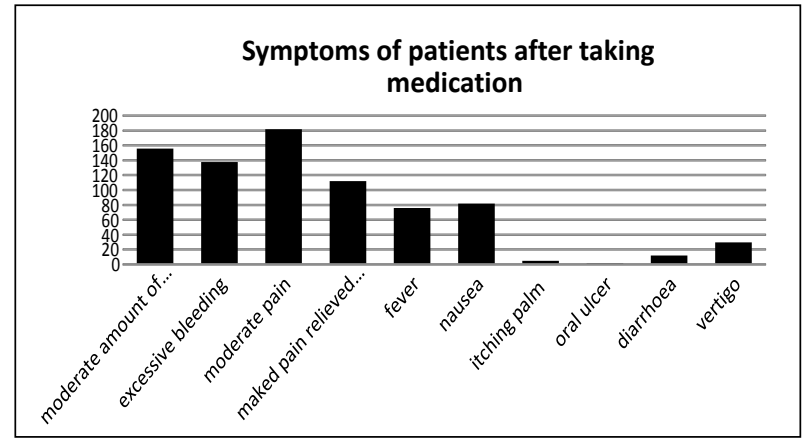

Fig 2: patients complains after taking MRM kit

Table: Socio-demographic Characteristics

Age in years

\begin{tabular}{lc} 
Range: $14-43$ & Mean age:29 \\
\hline Age & No. of EMAs \\
\hline 14-19 years & 25 \\
20-25 years & 102 \\
26-31 years & 107 \\
32-37 years & 46 \\
38-43 years & 14 \\
\hline
\end{tabular}

\section{Length of gestation}

Gestational age: 5-9 wks Mean gestational age: $6.3 \mathrm{wks}$

\begin{tabular}{ll}
\hline Gestation & No. of EMAs* \\
\hline 5 weeks & $56(19 \%)$ \\
6 weeks & $111(37.8 \%)$ \\
7 weeks & $88(39.9 \%)$ \\
8 weeks & $35(11.9 \%)$ \\
9 weeks & $4(1.4 \%)$ \\
\hline
\end{tabular}

\section{Education}

\begin{tabular}{ll}
\hline Primary incomplete & 13 \\
Primary & 48 \\
Secondary & 116 \\
Higher secondary & 86 \\
Graduation or higher & 31 \\
\hline \hline Number of pregnancies & \\
\hline $0-2$ & 72 \\
$3-4$ & 126 \\
$4+$ & 96 \\
\hline
\end{tabular}

\begin{tabular}{ll}
\hline Occupation & 25 \\
\hline Housewife & 186 \\
Service & 41 \\
Student & 38 \\
Others & 29 \\
\hline \hline
\end{tabular}

FP Methods used

$\begin{array}{ll}\text { Pill } & 82 \\ \text { Condom } & 140 \\ \text { Injectable } & 38 \\ \text { Other* } & 14 \\ \text { Nil } & 20\end{array}$

Percentage distribution of women who had a menstrual regulation with medication, selected responses:

\begin{tabular}{lc}
\hline Responses & $\%$ \\
\hline Satisfaction & \\
\hline Satisfactory & 90 \\
Natural & 8 \\
Unsatisfactory & 2 \\
\hline Overall side effect & \\
\hline Acceptable & 87 \\
Natural & 8 \\
Unacceptable & 5 \\
\hline
\end{tabular}

\section{Discussion}

Despite relatively high contraceptive prevalence (61\%) compared to other developing countries, Bangladesh continues to have a low utilization of long term or permanent contraceptive methods, a high discontinuation rate, and unmet needs for family planning 16 . Some women in Bangladesh resort to menstrual regulation (MR) to avoid unwanted and unplanned childbearing.

In Bangladesh, MR is legally provided through MVA by registered service providers (e.g. paramedics, FWVs, physicians) in primary, secondary, and tertiary government facilities, select NGOs, and private facilities. Because of the stigma, shame, and fear of disclosure associated with MR, however, women often turn to illegal measures and substances for abortion that are ineffective, 
harmful, and life threatening. In these circumstances, medical abortion using drugs is an important alternative to surgical methods4. Mifepristone followed by a prostaglandin analog, most commonly misoprostol, has been shown to be safe and effective up to nine weeks (63 days) of pregnancy and is the method of abortion recommended by the World Health Organization.

Several studies showed the rates of MRM success 93-98\% (17-21). A study by Alam A et al 2013, in Bangladesh used $200 \mathrm{mg}$ of mifepristone followed by $800 \mathrm{mcg}$ of misoprostol found $93 \%$ women evacuated the uterus without surgical intervention and overall $92 \%$ were satisfied with use

In a study by Beverly Winikoff, 1995 compared surgical abortion to medical abortion and found overall $84 \%$ of the women enrolled said they would prefer a medical abortion. Success rates were high for both methods (100\% for surgical abortion and 97\% for medical abortion), but bleeding lasted about twice as long for women who had a medical abortion23. In our study, we found most of the patients complained of moderate bleeding (53\%) and pain $(62 \%)$ after taking medication but some of them revealed excessive bleeding (47\%) and marked pain relieved by pain killer (38\%). Though there were some complications in this method, $87 \%$ patients told overall side effects were acceptable and $8 \%$ said natural \& only $5 \%$ found unacceptable. On interview about the satisfaction of the patients in using this method for early termination of pregnancy, $90 \%$ patients were satisfied with this method and they said they will advise their friends and relatives for using this method for early termination of pregnancy.

\section{References}

1. Fathallaa MF \& Cook RJ. Women, abortion and the new technical and policy guidance from WHO. Bulletin of the World Health Organization 2012;92:712.

2. Ahman E, Shah IH. New estimates and trends regarding unsafe abortion mortality. International Journal of Gynecology and Obstetrics 2011;115:121-126

3. Global burden of disease 2004 update. Geneva: World Health Organization; 2008.
4. Singh S, Hossain A, Maddow-Zimet I, Bhuiyan HU, Vlassoff M, Hussain R. The incidence of menstrual regulation procedures and abortion in Bangladesh, 2010. International Perspectives on Sexual and Reproductive Health. 2012:122-32.

5. Abortion With Self-Administered Misoprostol: A Guide For Women International Women's Health Coalition, Gynuity Health Projects 2010.

6. Creinin MD, Fox MC, Teal S, et al. A randomized comparison of misoprostol 6 to 8 hours versus 24 hours after mifepristone for abortion. Obstet Gynecol 2004; 103: 851-859.

7. McKinley C, Thong KJ, Baird DT. The effect of dose of mifepristone and gestation on the efficacy of medical abortion with mifepristone and misoprostol. Hum Reprod 1993; 8: 1502-1505.

8. Middleton T, Schaff E, Fielding SL, et al. Randomized trial of mifepristone and buccal or vaginal misoprostol for abortion through 56 days of last menstrual period. Contraception 2005; 72: 328-332.

9. Royel College of Obstetricians and Gynaecologists 2001; The care of women requesting induced abortion. Evidence-based guideline no.7.London: RCOG Press.

10. Winikoff B et al., Two distinct oral routes of misoprostol in mife- pristone medical abortion: a randomized controlled trial, Obstetrics \& Gynecology 2008; 112(6):1303-1310.

11. vonHertzen $\mathrm{H}$, Honkanen $\mathrm{H}$, Piaggio $\mathrm{G}$ et al. WHO multinational study of three misoprostol regimen after mifepristone for early medical abortion. I: Effecacy. BJOG 2003; 110(9), 808-818.

12. Hamoda H, Ashok PW, Flett GM, Templeton A. A randomized controlled comparison of sublingual and vaginal administration ofmisoprostol for cervical priming before first-trimester surgical abortion. Am J Obstet Gynecol 2004; 190: 55-59.

13. Winikoff B et al., Safety, efficacy and acceptability of medical abor- tion in China, Cuba and India: a comparative trial of mifepristone- misoprostol versus surgical abortion, American Journal of Obstetrics \& Gynecology 1997; 176(2):431-437.

14. K arki C, Pokharel H, Kushwaha A et al. Acceptability and feasibility of medical abortion in Nepal. International journal of gynaecology and obstetrics 2009; 106 (1), 39-42. 
15. Murthy A \& Creinin MD. Pharmacoeconomics of medical abortion : a review of cost in the United states, Europe and Asia. Expert Opinion in Pharmacothereapy 2003; 4(4),503-513.

16. NIPORT, Mitra and Associates, and ICF International, Bangladesh Demographic and Health Survey, 2011: Preliminary Report, Dhaka, Bangladesh: NIPORT and Mitra and Associates; and Calverton, MD, USA ICF International, 2012.

17. Middleton T et al., Randomized trial of mifepristone and buccalor vaginal misoprostol for abortion through 56 days of last menstrualperiod, Contraception 2005; 72(5):328-332.

18. Winikoff B et al., Two distinct oral routes of misoprostol in mifepristonemedical abortion: a randomized controlled trial, Obstetrics\& Gynecology 2008; 112(6):1303-1310.

19. Fjerstad $\mathrm{M}$ et al., Effectiveness of medical abortion with mifepristone and buccal misoprostol through 59 gestational days. Contraception 2009; 80(3): 282-286.
20. Chong E et al., A randomized controlled trial of different buccalmisoprostol doses in mifepristone medical abortion. Contraception 2012; 86(3): 251-256.

21. Blum $\mathbf{J}$ et al., Comparison of misoprostol-only and combinedmifepristone-misoprostol regimens for homebased early medicalabortion in Tunisia and Vietnam. International Journal of Gynaecology\& Obstetrics 2012; 118(2):166-171.

22. Alam A, Bracken H, Johnston HB, et al. ,Acceptability and Feasibility of Mifepristone-Misoprostol For Menstrual Regulation in Bangladesh. International Perspectives on Sexual and Reproductive Health 2013; 39(20):79-87.

23. Winikoff B. Acceptability if medical abortion in early pregnancy. Family Planning Perspective.1995; 27:142148. 